\title{
CHANGING TRENDS IN HEALTH PROFESSIONS EDUCATION: THE NEED TO STRIKE A RIGHT BALANCE!
}

Fifty years ago, Kothari Commission on Education observed: "The destiny of India is now being shaped in her classrooms." The statement holds good even now. No one can deny that education is the most powerful tool for nation building. Health is an essential requirement. Health Professions Education, therefore, occupies foremost agenda for a growing nation. It is all the more important agenda for a Health Sciences University such as Sri Balaji Vidyapeeth which strives to remain in the forefront of health professions education in order to produce a high caliber human resource in medical, dentistry, nursing and allied health sciences. However, trends in education change with times. Often they may cause conflict between the new thoughts and old mindset. How do we catch up? It seems reasonable to examine them dispassionately and strike a right balance. Consider the nature, scope and focus of medicine itself.

Education in health profession has been influenced not only by the nature of medical science and research, but also by other factors such as changing societal needs/aspirations, socio-economic development, political agenda and most importantly the impact of information technology. Though the response of the education system has been slow, it has been intensified during the last couple of decades. The shift from 'informative learning' to 'transformative learning' has influenced designing of a competency based approach to learning and training. Conventional teaching is being supplemented with integrated teaching and problem based learning. New areas of competency such as practice based learning \& improvement, interpersonal communication, professionalism including ethical behavior, and systems based practice have emerged in addition to traditional medical knowledge and patient care. These developments have triggered a shift in the scope and modalities of assessment. Assessment is considered as a tool for 'improving' rather than 'proving' students' learning outcome. Educators have begun to search new modalities of assessment such as e-portfolio to ensure day to day assessment and monitoring of progress. They are also becoming familiar with the use of Multi-Source Feedback ( $360^{\square}$ assessment) to capture the whole gamut of competence. A right balance between conventional assessment and innovative methods such as Workplace Based Assessment is therefore a much needed step.

Yet another unprecedented development is the growth of student enrolment, expanding curriculum, and shortage of faculty to run the system. While the formal education has become expensive, inadequate and too demanding for the teachers, new forms of e-learning and their incorporation in myriad forms such as distance learning, blended learning and MOOC have opened up new windows of opportunities. The traditional courses are being supplemented with new courses with flexible learning opportunities based on Choice Based Credit Systems (CBCS), which are becoming popular among student community. The new revolution is expected to change the role of teachers as well as the students. The traditional role of teacher as an authority or expert is being challenged by new role as feedback provider, mentor and a coach to facilitate student learning. Since this movement is almost 'threatening', what is desirable is a smooth transition of striking a right balance!

Through this special issue of Annals of SBV dedicated to the health profession, we have tried to capture the changing trends in health profession. The articles reflect the voices expressed by some of the educational stalwarts in the country who participated in a National Conference on Changing Trends in Health Professions Education (18-20, August 2016) organized by the SBV. We have also provided equal space for other educators across the health profession to air their views and share their wisdom. We hope the plethora of articles would stimulate further discussions which will help our University in contributing to the health professions education in the country. Special thanks are due to all the contributors, our team members and specially the leaders of SBV who hold no bar in stimulating our academic journey to new a new height.

Adkoli B.V.

Sri Balaji Vidyapeeth - Mahatma Gandhi Medical College and Research Institute Campus, Pillaiyarkuppam, Puducherry-607403, INDIA 